\title{
Increasing resilience by holistic catalyst to further thriving communities
}

\author{
L. H. Shamsul, S. S. Zubir, F. R. Razali, Z. Yahya \& F. Kholid \\ Centre of Studies for Architecture, Faculty of Architecture, \\ Planning and Surveying, University Teknologi MARA, Malaysia
}

\begin{abstract}
Man has never made any material as resilient as the human spirit and this represents his resiliency to ensure the survivability of the community. Urban development creates benefits for people and in the case of Ho Chi Minh City, an enormous wave of new developments are being executed to accommodate the policy of the nation's economic growth for the next two decades. However, the conventional developments of the city neglect the consequences which will devastate the local population and heritage that will then culminate into a city without an identity. This paper delineates an urban design exercise that will grasp the core activities of the locals where the crucial factors such as their culture, economics and quality of life are vital for survival with the current developments. Their resiliency will ensure the heritage of the place and identity remains intact in the long run and creates a balance development for the city. The current decaying neighbourhood is healed with effective urban intervention phases that will improve the economic status of the individual which then translate to the community and subsequently the place itself hence rejuvenating the crumbling local society in Phurong four vicinity. By adapting a theoretical approach of the machine and organic models, innovative housing typologies and spatial reprogramming will be generated to meet future demands and subsequently improves the public realm of this district.

Keywords: housing, public park, retail blocks, waterfront, economy, resiliency.
\end{abstract}

\section{Introduction}

Ho Chi Minh City is a remarkable place where the experimental use of the public realm has broadened the traditional notion of a living city and suggests innovative 
solutions for contemporary needs. This urban design escapade demands an innovative strategy that is responsive to the fluid and amorphous conditions of the engaged urban environment. The city's various lucrative activities are the main components that contribute to the increased in population and expansion of the central business district [1]. Its extensive historical sites and vast expanse of architectural and cultural heritage becomes a popular destination for tourists to visit [2].

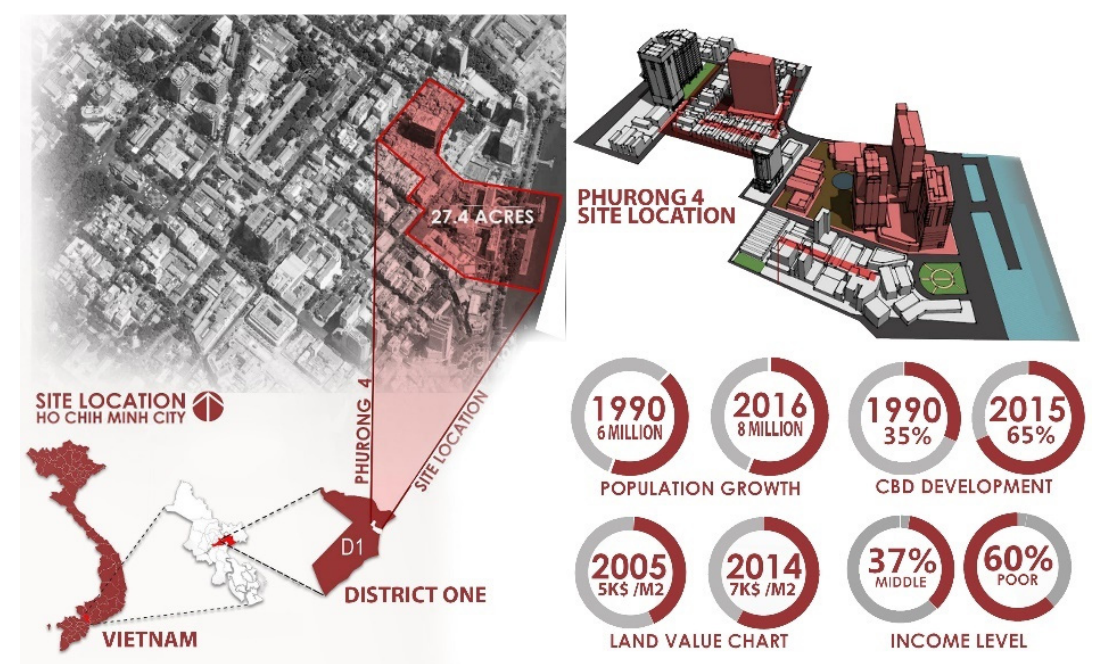

Figure 1: Location plan of Phurong 4 within the context of the city.

The proposed urban design intervention is located in Phurong 4 of District One (as shown in Figure 1), which is currently encroaching into the adjacent high-end and trendy neighbourhoods, which have the potentials of becoming a haven for tourism. Hotels and offices at the eastern end near the Saigon River and existing residential blocks on the western side surround the 27.4 acre area. The residential blocks have been there since 1802, which dates back to the Ngu Yen dynasty where people worked in their homes or nearby. 'Post- modern' styled commercial towers adorned its skyline with intermittent decaying residential blocks with 'rat tunnel' alleyways, retail shop lots and pockets of public parks constitute the waterfront promenades along the Saigon river. This area is earmarked for future urban rejuvenation and currently many of the land are developed into mixed residential and commercial blocks replacing the fine-grained lots of the traditional neighbourhoods. The new high-rise buildings complement the city's development but on the other hand lead to gentrification. Existing tenants would have to vacate as rental are increasingly expensive contributing a decline in business activities. People preferred to do their commercial activities in the nearby Ben Thanh market and Nguyen Hue area where the places are still imbued with the traditional ambiance of the old neighbourhood. New developments also contribute to the 
displacement of skilled workforce in this area as they have to travel a long distance to their work place [2].

The waterfront is not developed to its fullest potentials in celebrating the place [8]. Therefore, the opportunity for an urban intervention proposal to rejuvenate this neighbourhood and at the same maintaining the local cultural identity becomes the crux of this paper. In addition, Phurong 4 needs to be embedded with innovative urban design intervention due to the fact that it must complement the newly planned Thu Thiem in District 2 which is soon to be realized as an extension in terms of the activities, form and image of the City's central business district across the river.

\section{Site potentials and dilemmas}

Displacement of local community leads to the diminishing business activities for small and medium size entrepreneurs is the main problem of the study area. As shown in Figure 2, the locations in Phurong 4 where the dilemmas are rectified. The emergence of recent development has increased property values of the area thus prompted local communities to dispose their properties and moved to more affordable district. The rental rates for existing affordable housing is projected to increase and will further burden the low and middle-income group there. Furthermore, the site lacks public amenities and distinguishable interactive nodes for the community. Most of the public spaces along the waterfront are used for parking and garbage dumpsite. To overcome the problems, a series of tactical strategies will be formulated from a holistic approach to generate urban design proposals for the site.
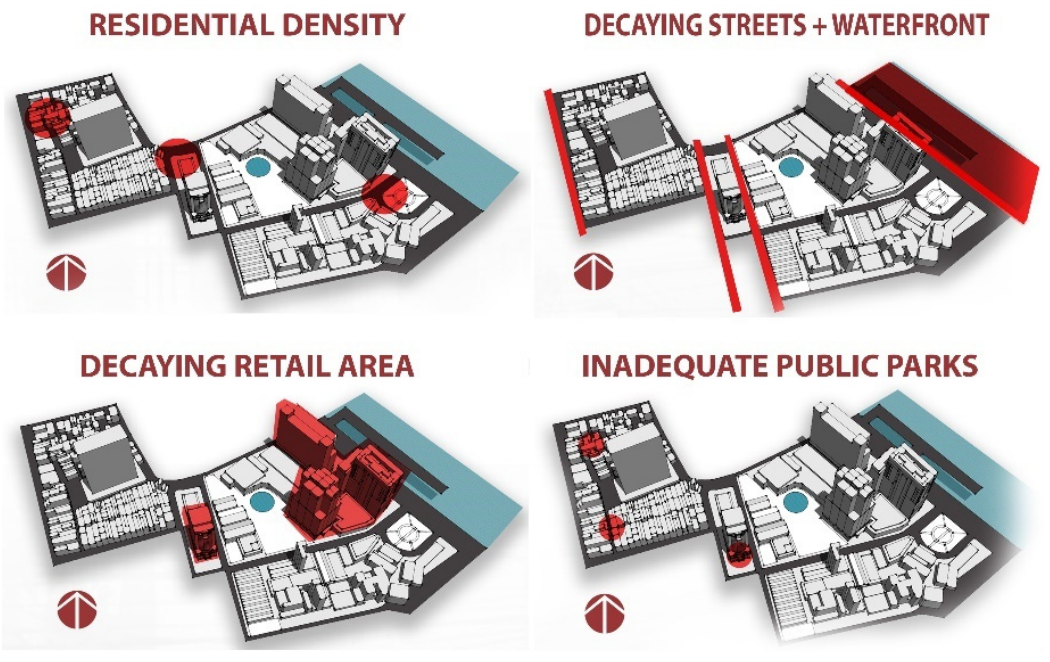

Figure 2: Indicates the site dilemmas location in Phurong 4. 


\subsection{Retail shop-lots: decay vs. revivify}

The decaying retail shop-lots are most prevalent due to the low business turnovers that further aggravate the lack of maintenance. Local business activities have been taken over by the newly built shopping malls that offer more choice for people and usually the place is more comfortable. This gradually will make the traditional shop-lots empty and chances are that the neighbourhood will be planned as another campus-like development which disrupt the continuity of the existing prevailing urban culture. Therefore, a strategy is needed to retain the existing retail shop-lots with new and innovative typologies for the urban intervention of the place [5]. The retail shop lots are majority owned by the locals living nearby at the surrounding housing blocks. The shop lots are vital to be rejuvenated, as it will be the sole generator of income for the locals to sustain their livelihood. New re-adaptation of uses from the existing building stock needs to be generated so that a juxtaposition of core programmes that emphasize sustainable development with specific focus on traditional cultural continuity could be realised [7].

\subsection{Low and medium cost residential: soaring density vs. local's novelty}

The increasing in population of Ho Chi Minh City would eventually make the city centre denser. People have to commute long distances to their work place and this becomes unsustainable especially for the low and middle-income groups, as they have been displaced by the disparity of new urban development. As the current state of urban development is capital driven, new properties are not within the reach of many locals and much of the traditional core activities of the neighbourhood have been displaced. Furthermore, the lack of affordable housing units for the locals to retain their business activities is non-existent in the newly developed areas thus create a rupture in the continuity and survival of the endemic culture of the place [10]. The increase in population in the inner city established new avenues of potentialities for innovative affordable housing typologies to be generated that are able to co-exist and merge with the new urban fabric [3]. The housing units must be affordable to prospective buyers with appropriate unit sizes, sufficient public amenities, with low cost materials and construction techniques to overcome the inadequate housing demands. It is also necessary to incorporate the hidden dimension of the space-time matrix of the local cultural activities as this becomes an important catalyst in the urban design for sustainability and survival of the community's heritage in the near future.

\subsection{Public spaces: inadequate vs. specifying}

The lack of public parks in this neighbourhood diminishes the essence of a good urban place [1]. At the moment, pockets of public parks are mostly located within the boundaries of the hotel area, which is only used occasionally by the tourist. This is a waste of space as it goes against the rationale of people using it and the amount of time that were supposed to be given to the locals, were not being utilised by the tourist. Pockets of public open spaces should be connected as nodes to elevate street-life activities. It is imperative that the programmes of these spaces 
should be made more permeable as to flow into the street alleys. This is a mechanism for sustaining the economic growth and cultural heritage thus improving the quality of life of the locals and tourist alike [2].

\subsection{Riverside space quality: diminishing vs. rejuvenation}

The western part of the site along the Saigon River is vacant land without supporting programme of activities to the existing urban fabric. At the moment, the waterfront is used as a dumping ground for garbage and illegal parking spaces, which does not contribute to the aesthetics of the townscape [8]. Although it is in the state of despair, the site has the potential to be rejuvenated with various typologies of water-based programmes and transportation related activities. Currently Saigon River is widely being used as a major mode of transportation for naval barge and ships. Eventually, the waterfront will complement future activities in District 2 across the river, which is due for completion in 2025 [8]. The area could be connected not only by physical means but also through series of connecting vista that establish important visual linkages between the two districts.

\section{Theoretical background}

The theoretical underpinning for this urban design intervention is largely derived from the organic and machine model. The two models are further expanded into four theoretical approaches depending on the appropriateness to the specific problem area. As shown in Figure 3, holistic urban design tactics will be employed to generate development strategies for the residential, retail and the public realm.

\section{1 "Communal advocacy"}

In regenerating the site from decaying and to promote a sustainable environment, this concept is generated from the synthesis of the organic model as a holistic coexistence of nature and human collaborating in solving urban and environmental breakdowns [2]. Communal advocacy is where the community established various activities in the development programme focusing on aspects in rejuvenating the natural setting with urban elements that could heighten the sensory experience of the users and eventually contribute in the transformation of the urban fabric of the site [5]. The insertion of small-scale public hubs would create active or intimate street-life activities as people can choose their preferred places to be alone or socialised. Since the core component in ensuring sustainability is the local people, their day-to-day attitudes that also form the culture of the society need to be preserved in the landscape of the place. Hence, their cultural longevity will also impact the sustenance of the lived environment, ingrained in the genius loci of the neighbourhood. The insertion of streetscape amenities and facilities would contribute to an active street life creates a successful urban space hence rejuvenating the image, activities, physical and spatial composition of place [5]. 


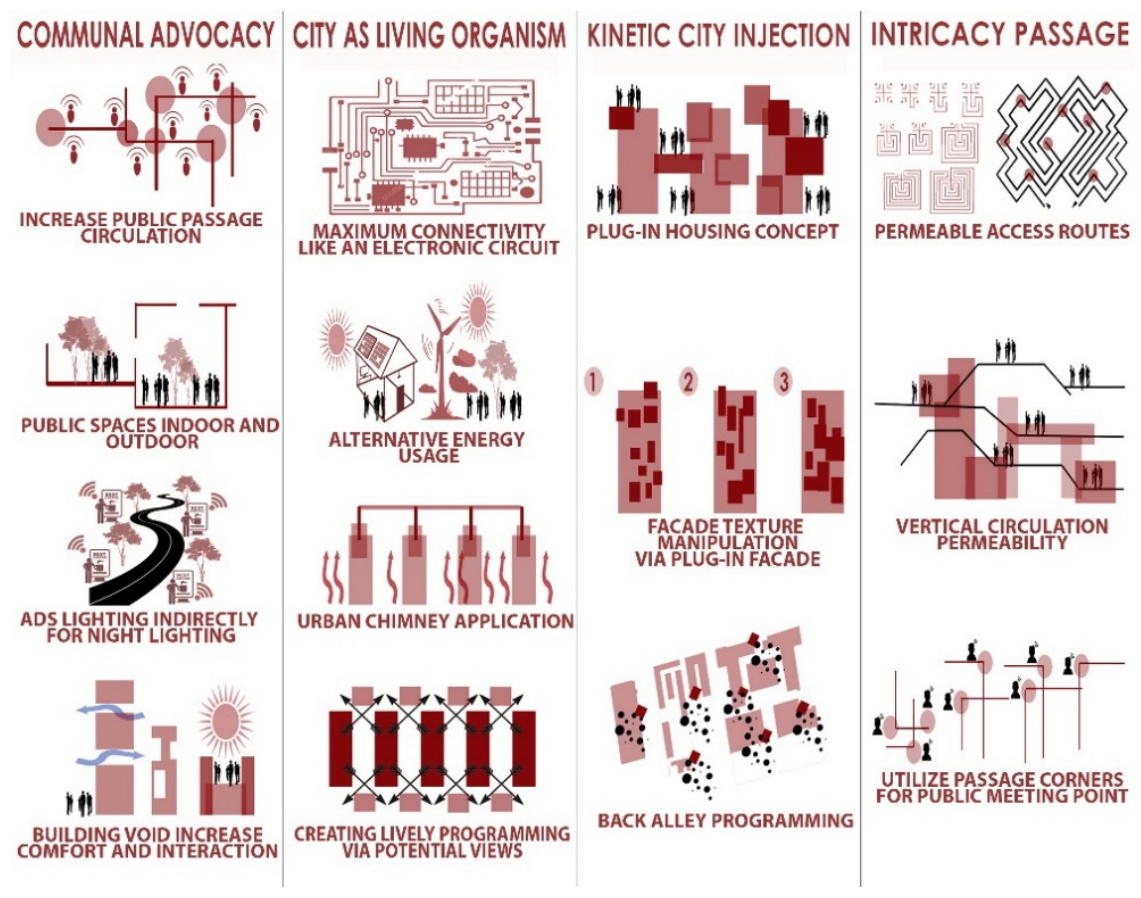

Figure 3: Theories converted into diagrams and explanation.

\subsection{City as a living organism}

This theory focuses on the imperative of spatial spaces to efficiently link people from the interior to the exterior urban spaces and visa-versa. Connectivity just like a cell must be well coordinated where people can interact on a daily basis where social communication/interaction could create dynamic spaces that enhance connectivity. By strategically inserting series of minor and major nodes with multiple programming would further enhance the permeability that offers wider dimensions in experiencing the neighbourhood [1]. The analogy of the living organism can also be represented as economic vitality in promoting the development of the area as it portrays commercialism as an identity which has a positive impact on the urban intervention [2]. The holistic balance of this approach would result in a positive transformation on any urban setting.

\section{3 "Kinetic city"}

The idea revolves around the plug-in city concepts where an urban structure could be constructed using flexible, permeable and dynamic components. Derived from the machine model, the components could be easily oriented to form movable urban structures, which can be added on to meet high density urban living in the near future [5]. The intervention applies to the residential areas where the idea of the plug-in city is deemed to be relevant in this neighbourhood due to lack of space and high population [10]. The kinetic characteristic of the urban form also reveals 
the ever-changing typologies to the units, which can be manipulated by using flexible façade components. The theory exudes the idea in giving a sense of excitement to visitor/end users to the area, to experience the ever-changing representation of the urban setting that negate dullness and boredom creating a sense of thrills and excitements of the place.

\section{4 "Intricacy of passages"}

The pattern and connectivity of pedestrian routes in an urban setting gives an enormous impact towards the experience of the place which are converted into memories and thought processes by the individual [9]. The theory stresses on the importance of the way-finding and the urban planners grip in controlling the routes to emulate the virtual dimensions in which an individual could digest the fifth sense of the area via walkways and its response to the physical layout of the urban scape [9]. An efficient connection within spaces would evoke an efficient circulation to identify the most potential points for programming and an overall gesture to create systematic routes in the urban intervention phase [4].

\section{Urban design intervention}

The proposed urban intervention is to develop in phases. The first and major intervention is to insert new typologies for affordable housing using industrialised construction techniques to lure people not to move from the central business district due the inflating cost of living [3]. The next phase is by revivifying the retail shop lots with effective programming in retaining and strengthening their resiliency to continue living in the city that are not affected by the hike of land value and property development [5]. The next stage is to improve the quality of public parks for the local population to promote street level activities which reflects the essence of a good urban place [1]. The waterfront promenades will be installed with creative spaces as series of nodes with water related programmes [8] by transposing these core programmes would eventually establish this neighbourhood into a successful urban place and a model for other places to emulate. The detail components of the interventions are as follows.

\subsection{Re-use, re-programming and re-branding of retail shop lots}

It is imperative to have a complete inventory of the conditions of the existing buildings in the retail area in order to specify the core programmes in sustaining the continuity of the urban heritage of the neighbourhood [11]. As shown in Figure 4, the inventory, category one is classified as vacant blocks that are structural stable and with all basic infrastructure facilities. Category two are buildings which need repair on their structure and basic amenities. The third category are blocks which are vacant and not fit for any adaptive re-use programming which are likely to be demolished [1]. The retail shop lots will be installed with new and more vibrant programming which targets a broader based clientele. Vacant blocks will be re used and refurbished interiorly and exteriorly to enhance the appearance that meets the theme of the rejuvenation project. 


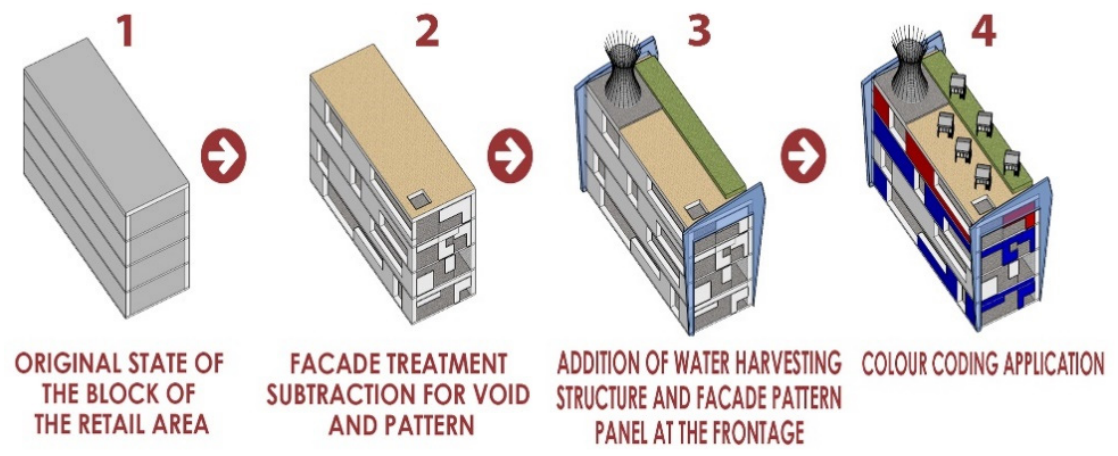

Figure 4: Diagram sequence of reusing abandoned shop lots.

\subsection{Injection of public area pockets}

The vacant blocks which are demolished will be converted into new public housing with intermittent pockets of public spaces. The spaces are used 24 hours a day to accommodate the needs of the visitors and locals which changed accordingly to time and occasions. During the day, the open spaces are left for playground and social areas while at night, the spaces will be transformed into night market and an open gym $[4,5]$.

\subsection{Way finding routes and pedestrian efficiency}

The way finding routes are developed from the theory of intricacy of passages to establish efficient routes and sense of orientation for pedestrians. It enhances the cognitive mental construct of visitors and also contributes to a more holistic representation of the urban scape to the community [9]. Efficient way finding will help people reduce time in navigating themselves to their intended locations. Figure 5 illustrates the passage and circulation strategies [5].

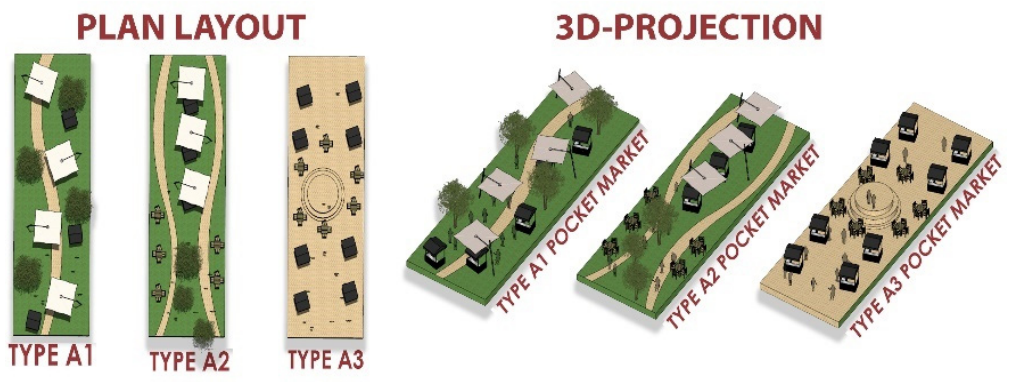

Figure 5: Typology and programming of pocket public spaces. 


\subsection{Colour coding retail blocks application}

Retail blocks in the old shop lots area are refurbished by installing colour screens which are coded base on the intended programmes [7]. Besides creating the exterior more attractive with the incandescent properties it also serves as an indirect lighting at night saving cost on street lightings [1] as shown in Figure 6.
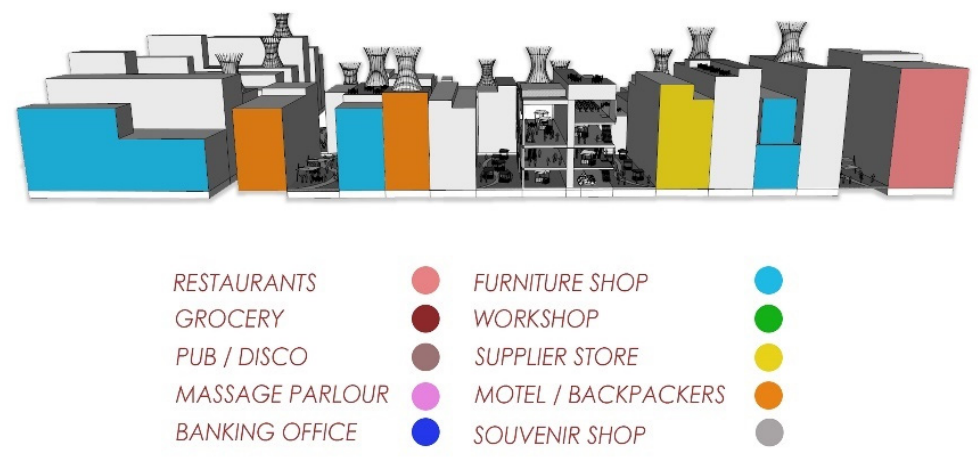

Figure 6: Colour coding shop lots diagram.

\subsection{Plug-in residential blocks intervention}

The increase in population leads to a higher demand in housing and to make it more affordable and sustainable; the industrialised systems of the plug-in housing units are employed. The residential plug-in blocks are best suited for high density development and with proper design and planning can contribute to a better quality of living experiences for the community [6]. The blocks are based on a modular dwelling system with basic necessities installed in every plug-in typology [10].

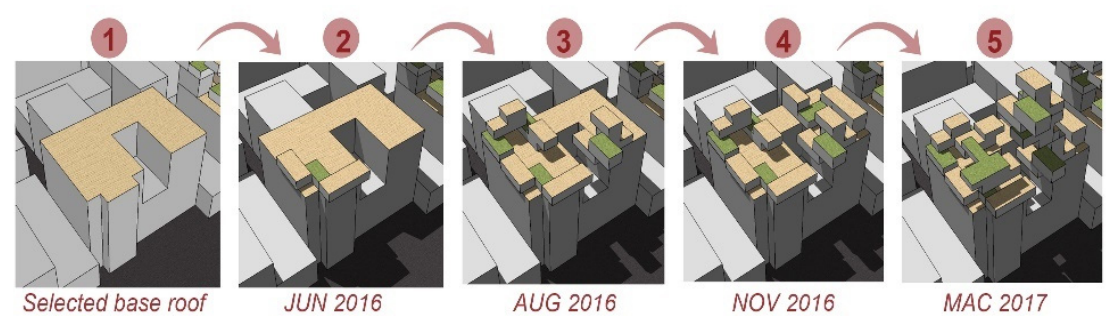

Figure 7: Timeline diagram of plug-in housing in Phurong 4.

\subsection{Residential recreational and mini farming programmes}

Each component of the newly designed public spaces in the residential housing zone will have its own recreational areas to boost the communal spirit between neighbouring blocks [3]. The idea of the mini farm is where the community is able 
to sustain their own food supply and also a source of income from the produce sold in nearby markets. Back lanes which are currently being infested with garbage and undefined spaces for crime to flourish, will be converted into entertainment and recreational hubs [10].

\subsection{Rejuvenation of "rocket house" tourism}

The term "rocket house" originated from the form of the shop houses, which project to five or six floors upwards without a proportionate configuration contributing to an interesting skyline silhouette of the urban sprawls in Ho Chih Minh City $[2,10]$. By generating varied typologies could commercially rejuvenate and contribute to the neighbourhood from the income generated from the tourism industry.

\subsection{Generative production of typologies for responsive design}

At the early stages of the design process, generating innovative typologies to respond to site specific issues confronts endless dilemma and potential in every sector of the site such as residential, retail blocks, public park plans, and waterfront design [3]. The aim is to verify and choose the most responsive solutions from the many generated typologies [5].

\subsection{Passive and active application of sustainable approach}

Sustainability is a common theme in any urban development where global awareness towards the conservation of the natural environment is paramount. Passive and active sustainable elements are implemented to each of the zoning areas to accommodate and utilise the environmental feature available at the site [11]. The strategies also give a positive occurrence in terms of lower cost of energy consumption for the area.

\subsection{Adaptive re-use of public realm}

Public parks are none existence for the locals in this neighbourhood as all of the green spaces are lawn owned by the hotel conglomerates which provide some public amenities and facilities to their clients which are used occasionally [7]. The re-programming of the new public parks will consist of a multi-dimensional space that caters for all ages and user needs such as wifi-spots, x-games, youth hangouts, food stalls, water features and other emerging facilities which are becoming popular attractions in Vietnam [9] (as shown in Figure in 5).

\subsection{Reanimate the waterfront location}

The waterfront region will be transformed into theme parks with water related activities supported by numerous terminals to connect District 2 on the opposite side of the river. The neighbourhood could reap the benefits from the newly planned District 2 in terms of employment in the construction industry. The waterfront will be equipped with spaces that are interactive for visitors and a 
catchment area for jobs to be allocated for the locals [8]. Figure 8 depicts the intervention sequence of the waterfront section.

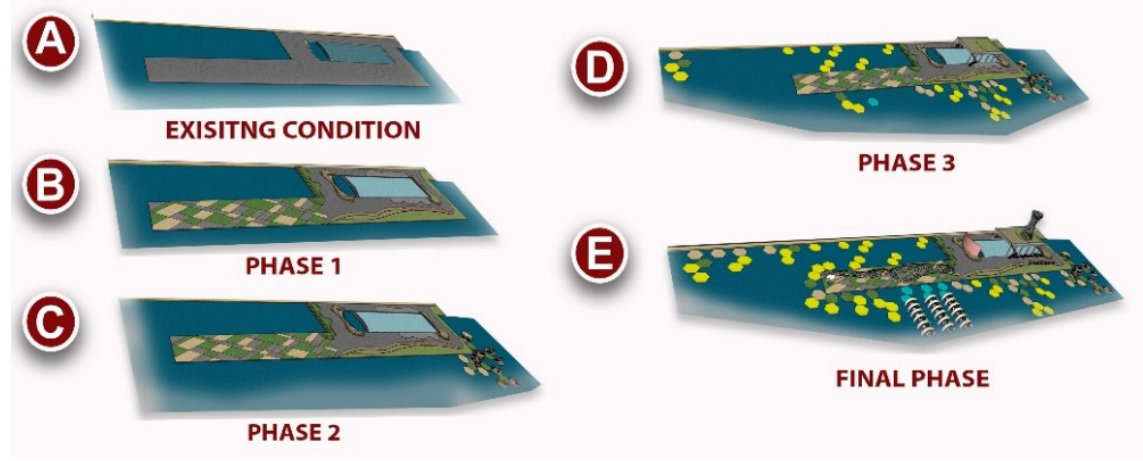

Figure 8: Diagram sequence of the jetty waterfront rejuvenation.

\subsection{Re-cycle and re-use of material for urban development}

The main aim of this approach is to lower the construction cost of the residential units where the materials from the demolished blocks will be recycled in the construction of the proposed plug-in housing scheme [10]. The waste which is produced in the area are reused in the hardscapes and landscapes of the area while others are dumped into furnaces of the housing blocks which will be converted into electrical energy [11]. Recycle bins with interactive messages are features in the urban setting to educate people, the importance of the recycling process. The recycled materials will generate less carbon foot print and secure a cleaner environment of the neighbourhood [11].

\section{Conclusion}

With all the intervention ideas in revivifying the resiliency of this urban neighbourhood, it is pertinence to stress the importance of sustaining the survival of local culture and heritage of the place. It constitutes the essence in the holistic approach to rejuvenate decaying vicinity. The main endeavour of the project is to untangle each arising issues in the urban context to ensure a balance in the overall development in which all traits of the area are being regenerated with their fullest potential capabilities. The intervention would be able to sustain the locals to reclaim their position in the city and lure more people in the area to further establish their influence and prosperity of the area. It can be foreseen that the ideas injected in this project are able to preserve the identity for future generations. It is our objective to ensure this approach to urban development could initiate a transformation where resiliency of traditional norms to be the source and inspiration for future urban development in Vietnam. As architects, we should be 
responsible for place-making, in order to recover a sense of meaning amid the onslaught of modernization.

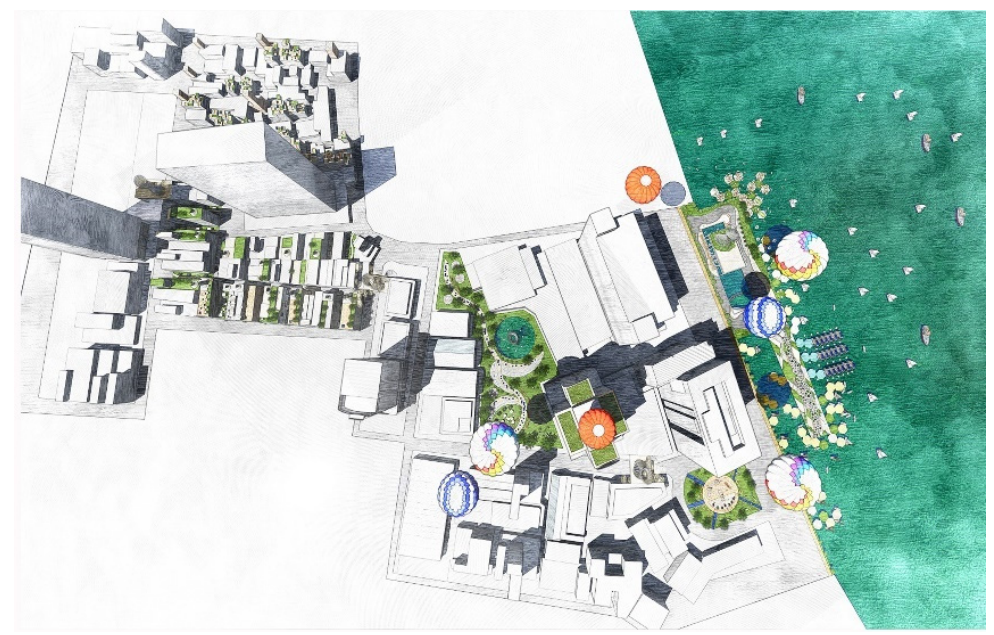

Figure 9: Bird's eye view of Phurong 4 urban intervention.

\section{Acknowledgements}

We would like to extend our utmost appreciation to the Faculty of Architecture, Planning and Surveying and the Institute of Graduate Studies, Universiti Teknologi MARA, in the provision of a grant for the realization of this paper.

\section{References}

[1] John Montgomery, 1998: Journal of Urban Design \& Urban Cultures chapter 5 [Online]. Available: http://www.urbanphilosophy articles.com [Accessed: 12 July 2016]

[2] Michael E. Smith, 2007: Form and meaning in the earliest cities: A new approach to urban planning Volume 7(10) pp: 200-250 [Online]. Available: http://www.jorunalarticle.com /Michael smith [Accessed: 07 July 2016]

[3] James R. Watson 2003: The rooftop project: The neighbourhood, the rooftop project, 2015. [Online]. Available: http://www.the-neighbourhood .com. [Accessed: 03 June 2016]

[4] Ron Heron 1985, "Insect City", from Detolf Industries Publications, Vol. 3, page: 56 [Accessed: 07 July 2016]

[5] John Madison, 1965: "Cosmic and Machine models cities" [Online]. Available http:/www.slideshare.net/mjohncox/cosmic-machine-andorganic-cities July 2013 [Accessed: 04 June 2016] 
[6] Quang Tran, "Project on the Vegan houses" [Online]. Available: http://www.archdaily.com/641621/vegan-house-block-architects [Accessed: 04 June 2016]

[7] Bernard Tshumi 2010, "Design approaches" Slideshare [Online]. Available http://www.slideshare.net/gauravshrinet3/bernard-tschumiphilosophy [Accessed: 06 June 2016]

[8] Umut Pekin Timur, "Urban Waterfront Regenerations" [Online]. Available: http://www.Urbanwaterfront.com/umit/pekin.htm [Accessed: 08 August 2016]

[9] Mark A. Foltz, 2009 “Wayfinding design principles" [Online] Available: http://wayfinding.design/principles-AIMT-Journal-articles [Accessed: 03 June 2016]

[10] Rebecca Paul 2012, “T-Tree Community of Prefab Pixel Homes” [Online]. Available: http://inhabitat.com/t-tree-a-towering-community-prefab-pixelresidences [Accessed: 15 June 2016]

[11] “Green Building 101: Sustainable materials and resources" [Online]. Available: http://www.usgbc.org/articles/green-building-101-sustainable material-sand-resources [Accessed: 05 June 2016] 